\title{
Inorganic Nanozymes: Prospects for Disease Treatments and Detection Applications
}

\author{
Peng Wang ${ }^{1+}$, Dongyu Min ${ }^{2 \dagger}$, Guoyou Chen ${ }^{1}$, Minghui $\mathrm{Li}^{1 *}$, Liquan Tong ${ }^{3 *}$ and \\ Yonggang $\mathrm{CaO}^{1 *}$ \\ ${ }^{1}$ Harbin Medical University-Daqing, Daqing, China, ${ }^{2}$ The Affiliated Hospital of Liaoning University of Traditional Chinese Medicine, \\ Shenyang, China, ${ }^{3}$ Department of General Surgery, The Fifth Affiliated Hospital of Harbin Medical University, Daqing, China
}

OPEN ACCESS

Edited by:

Lei Wang,

Harbin Institute of Technology, China

Reviewed by:

Xiaohui Yan,

Xiamen University, China

Lizeng Gao,

Institute of Biophysics (CAS), China

Minmin Liang,

Beijing Institute of Technology, China

*Correspondence:

Minghui Li

Imh17351@163.com

Liquan Tong

tla777666@163.com

Yonggang Cao

yonggangcaodr2014@163.com

${ }^{\dagger}$ These authors have contributed equally to this work

Specialty section:

This article was submitted to

Nanoscience,

a section of the journal

Frontiers in Chemistry

Received: 09 September 2021

Accepted: 07 October 2021

Published: 25 November 2021

Citation:

Wang P, Min D, Chen G, Li M, Tong L and Cao $Y$ (2021) Inorganic Nanozymes: Prospects for Disease

Treatments and

Detection Applications.

Front. Chem. 9:773285.

doi: 10.3389/fchem.2021.773285
In recent years, with the development of nanomaterials, a slice of nanomaterials has been demonstrated to possess high catalytic activity similar to natural enzymes and counter the dilemmas including easy inactivation and low yield natural of enzymes, which are labeled as nanozymes. The catalytic activity of nanozymes could be easily regulated by size, structure, surface modification and other factors. In comparison with natural enzymes, nanozymes featured with a more stable structure, economical preparation and preservation, diversity of functions and adjustable catalytic activity, thus becoming the potentially ideal substitute for natural enzymes. Generally, the are mainly three types containing metal oxide nanozymes, noble metal nanozymes and carbon-based nanozymes, owing various applications in biomedical, energy and environmental fields. In this review, to summarize the recent representative applications of nanozymes, and potentially explore the scientific problems in this field at the same time, we are going to discuss the catalytic mechanisms of diverse nanozymes, with the emphasis on their applications in the fields of tumor therapy, anti-inflammatory and biosensing, hoping to help and guide the future development of nanozymes.

Keywords: nanozyme, catalytic mechanisms, tumor therapy, anti-inflammatory, biosensing

\section{INTRODUCTION}

Enzymes are proteins or RNAs generated by living cells that are specific to their substrates with highly catalytic, who plays a key role in significant class of biocatalysts. With high catalytic efficiency and strong selectivity, enzymes have been widely utilized in disease diagnosis, biosensing and environmental protection (Chen and Arnold, 2020). However, natural enzymes are trapped of easing to denaturation under extreme conditions, high extraction cost and relative low utilization, which make it formidable to be applied in large-scale industrial production. Therefore, it is highly desirable and essential to find a natural enzyme substitute with strong and stable catalytic activity. In this case, inorganic nanozymes act as an emerging star has captured people's attention in recent decades (Wei and Wang, 2013). As early as 2007, Chinese scientists first discovered that $\mathrm{Fe}_{3} \mathrm{O}_{4}$ nanoparticles possess horseradish like properties, whose catalytic mechanism and efficiency are similar to horseradish peroxidase peroxidase (HRP) (Gao et al., 2007). This research breaks the long-held belief that inorganic materials are bioinert materials and opens the field of nanozyme research. Up to now, 540 kinds of nanomaterials have been reported to own enzyme-like activities (Wu et al., 2019; Wang L et al.,2019), including a total of 50 elements. Among them, 117 kinds of nanozymes have been utilized for disease treatments. So far, nanomaterials have been found to possess a variety of 


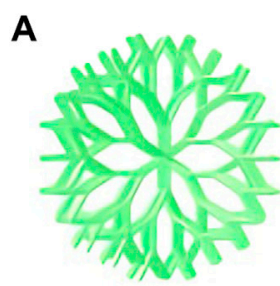

DNSN supports

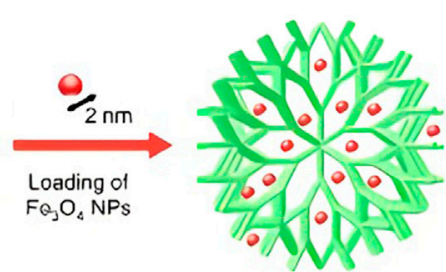

$\mathrm{Fe}_{3} \mathrm{O}_{4} \odot \mathrm{DMANN}$ nanocatalysts

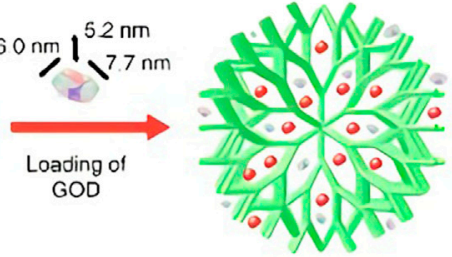

GOD $-\mathrm{Fe}_{3} \mathrm{O}_{4} \odot$ DMSNs nanocatalysts

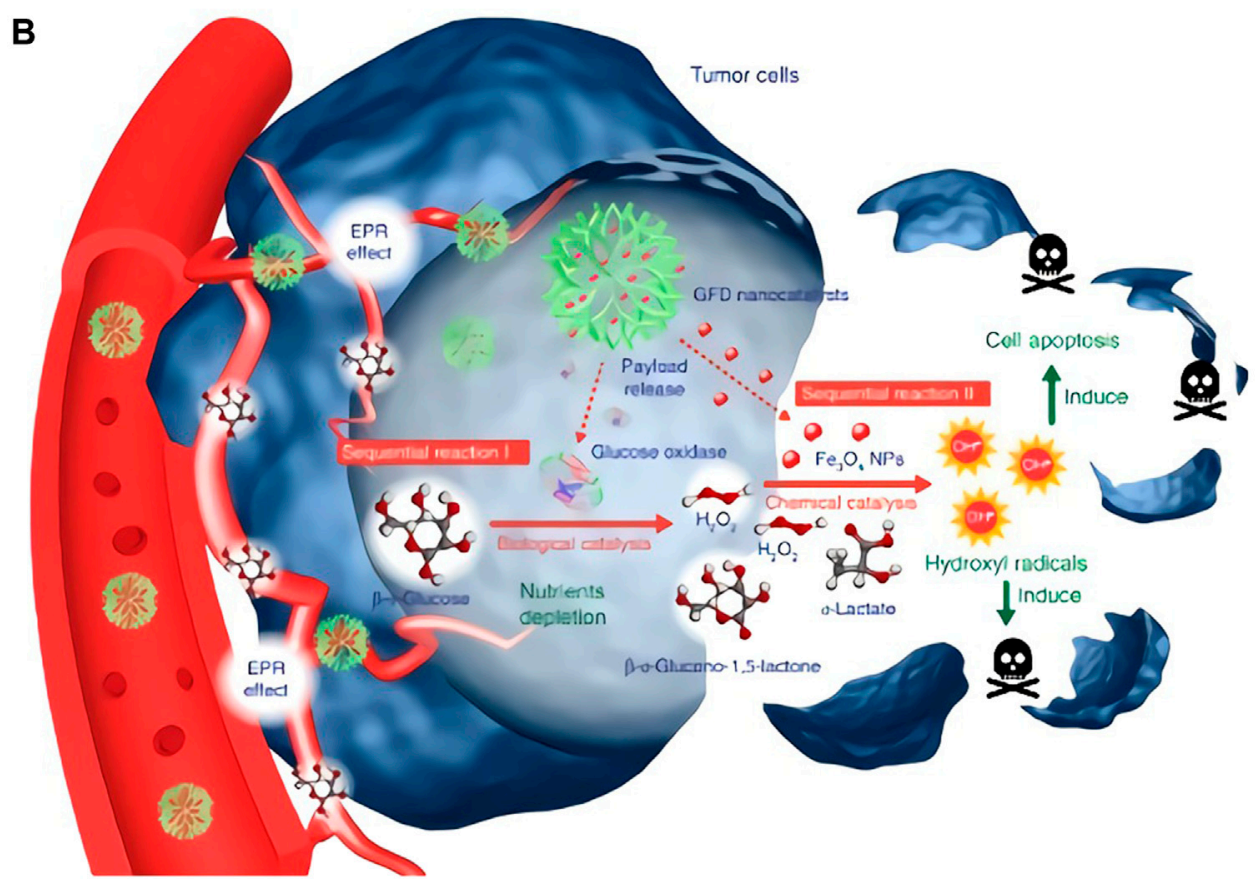

FIGURE 1 | Fabrication and catalytic-therapeutic schematics of sequential GFD NCs. (A) Synthetic procedure for Fe $\mathrm{O}_{4} @ \mathrm{DMSN}$ nanocatalysts and GOD$\mathrm{Fe}_{3} \mathrm{O}_{4} @$ DMSNs nanocatalysts. The sizes of the prepared $\mathrm{Fe}_{3} \mathrm{O}_{4}$ nanoparticles and adopted GOD are indicated in the scheme. (B) The scheme of sequential catalytictherapeutic mechanism of GFD NCs on the generation of hydroxyl radicals for cancer therapy. (a,b was reproduced with permission from Ref. (Huo et al., 2017). Copyright 2017 Nature Publishing Group.)

oxidoreductase activities, containing peroxidase (POD) (Li L et al., 2021; Li X et al., 2021; Liu C et al., 2021; Su et al., 2021; Zhang J et al., 2021), catalase (CAT) (Jia et al., 2019; Liu et al., 2021a; Wu et al., 2021; Xu et al., 2021; Zhang Y et al., 2021), superoxide dismutase (SOD) (Liu et al., 2021b; Liang and Yan, 2019; Lv et al., 2021; Sang et al., 2020; Yuan et al., 2021), oxidase (OXD) (Hu et al., 2021; Lin et al., 2021; Liu Y et al., 2021; Zhang J et al., 2021; Zhu et al., 2021) and glutathione peroxidase (GPx) etc. (Gao and Yan, 2013). The catalytic activity of nanozymes can be adjusted by changing size, structure, composition and surface modification of their nanomaterials (Meng et al., 2019). According to their components, nanozyme could be divided into metal oxide nanozyme, noble metal nanozyme and carbon-based nanozyme. This article will introduce the latest research progress of nanozyme the treatment of diseases from three therapeutic strategies. We hope to summarize the research situation of nanozyme in biomedical application (Table 1), so as to clarify the bottleneck problems in laboratory research and clinical transformation of nanozyme, making prospects for the future development of nanozyme.

\section{THE CONSTRUCTION OF NANOZYMES}

\section{Metal Oxide Enzymes}

Transition metals featured with variable valence and excellent stability, making them superior candidates for inorganic enzymes. The catalytic process of nanozymes involves electron transfer and valence changes, indicating oxidoreductase activity. $\mathrm{Fe}_{3} \mathrm{O}_{4}$ nanoparticles was first found to possess POD activity. The co-existence of ferric and ferrous ions endows it with superior POD and CAT properties (Figure 1) (Huo et al., 2017). It has been exploited that under acidic conditions, through the typical Fenton reaction, $\mathrm{Fe}_{3} \mathrm{O}_{4}$ could react with hydrogen peroxide to produce a large number of highly $\cdot \mathrm{OH}$. Upon neutral or alkaline conditions, it will promote the decomposition of $\mathrm{H}_{2} \mathrm{O}_{2}$ to produce $\mathrm{O}_{2}$. The reason is that $\mathrm{H}_{2} \mathrm{O}_{2}$ is more inclined to decompose into 


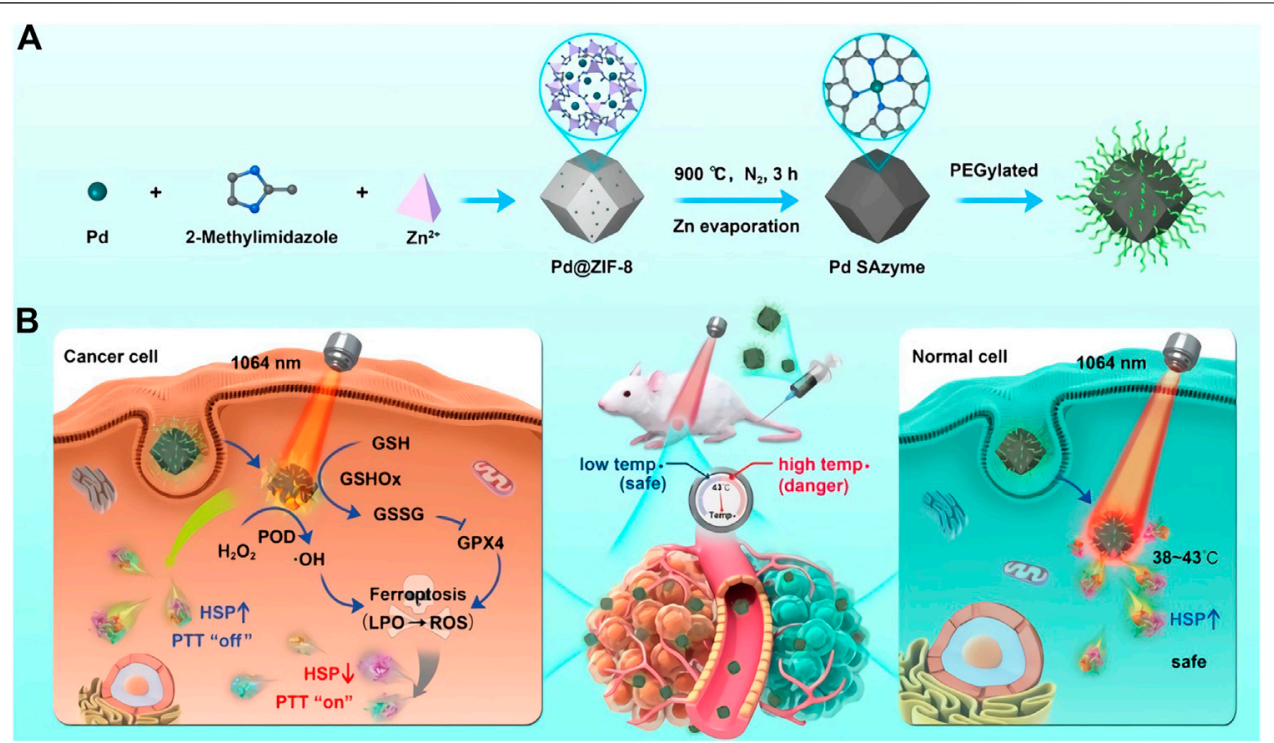

FIGURE 2 | Schematic illustration of the formation of PEGylated Pd SAzyme (A) and the mechanism of ferroptosis promoted by mild PTT (B). (A,B was reproduced with permission from Ref. (Chang et al., 2021). Copyright 2021 John Wiley and Sons.).

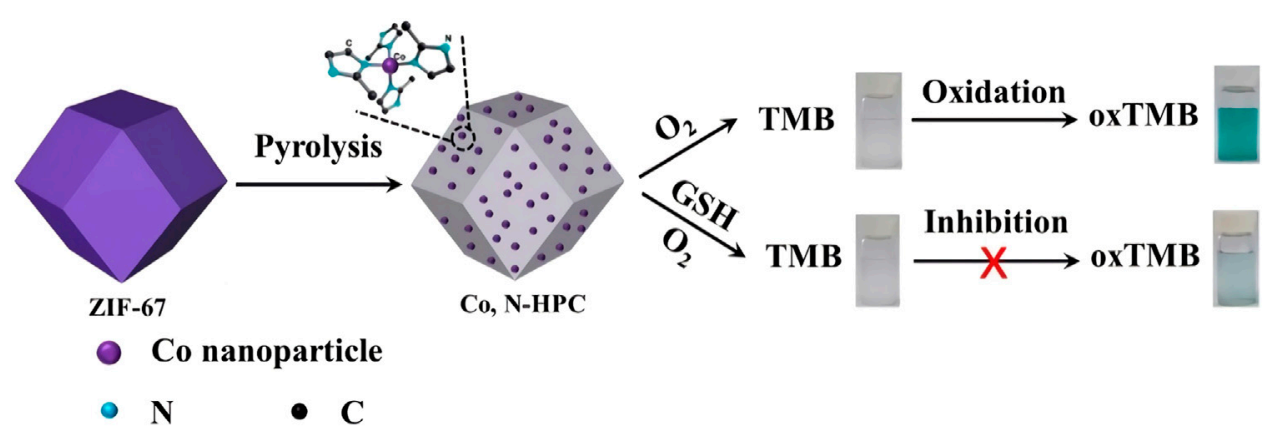

FIGURE 3 | The schematic diagram of $\mathrm{CO}_{3} \mathrm{O}_{4} @ \mathrm{Co}-\mathrm{Fe}$ hybrids was reproduced with permission from Ref. (Chen $\mathrm{H}$ et al., 2020). Copyright 2020 Elsevier.

$\mathrm{H}_{2} \mathrm{O}$ and $\mathrm{O}_{2}$ at higher $\mathrm{pH}$, while the $\mathrm{Fe}^{3+}$ in $\mathrm{Fe}_{3} \mathrm{O}_{4}$ just possess excellent catalytic ability, thus accelerating the reaction (Chen et al., 2012). What is similar to $\mathrm{Fe}_{3} \mathrm{O}_{4}$ are cerium oxide nanoparticles, at the neutral $\mathrm{pH}$ value, the content of cerium in the oxidation state +4 was higher, and the cerium oxide presented more significant CAT activity. However, at acidic $\mathrm{pH}$ and higher level of cerium atom on the surface of oxidation state +3 , cerium oxide presented reduced CAT activity, while its POD activity was more active, which can catalyze the reaction of TMB in the absence of $\mathrm{H}_{2} \mathrm{O}_{2}$ (Asati et al., 2009; Jiao et al., 2012). In addition, nanozyme with GPx properties have also aroused great attention. Ghosh et al. designed an active $\mathrm{V}_{2} \mathrm{O}_{5}$ nanozyme with redox properties and similar to GPx in four different forms. They demonstrated that the POD simulated activity of four orthogonal $\mathrm{V}_{2} \mathrm{O}_{5}$ nanozymes with different forms. Nanowire $\left(\mathrm{VN}_{\mathrm{w}}\right)$, nanosheets $\left(\mathrm{VS}_{\mathrm{h}}\right)$, nanoflowers $\left(\mathrm{VN}_{\mathrm{f}}\right)$, and nanospheres $\left(\mathrm{VS}_{\mathrm{p}}\right)$ can adjust the redox reaction by adjusting the size, shape and crystal plane, indicating that the activity is independent of their surface area, which provides an opportunity for the design and synthesis of nanomaterials with enzyme-like activity (Ghosh et al., 2018).

\section{Noble Metal Nanozyme}

Noble metal based nanozymes possess special optical properties, excellent chemical stability, adjustable enzyme-like activity and superior biocompatibility, which are the hot research materials in the field of nanobiology and medicine. Among them, $\mathrm{Au}$ and $\mathrm{Pt}$ nanozymes possess POD (Jv et al., 2010), SOD and CAT activities (He et al., 2013). Besides, Au quantum dots also possess glucose oxidase (GOD) activity, and experiments results demonstrated that the activity of GOD was negatively correlated with particle size, for the smaller the particle size presents the higher the GOD activity, which due to the fact that small particle sizes own larger surface area (Comotti et al., 2004). Different from the catalytic mechanism of electron transfer of transition metal ions, noble metal nanozymes are generally stable and no valence changes occur in the catalytic reaction, and SOD activity is due to thermodynamics and 

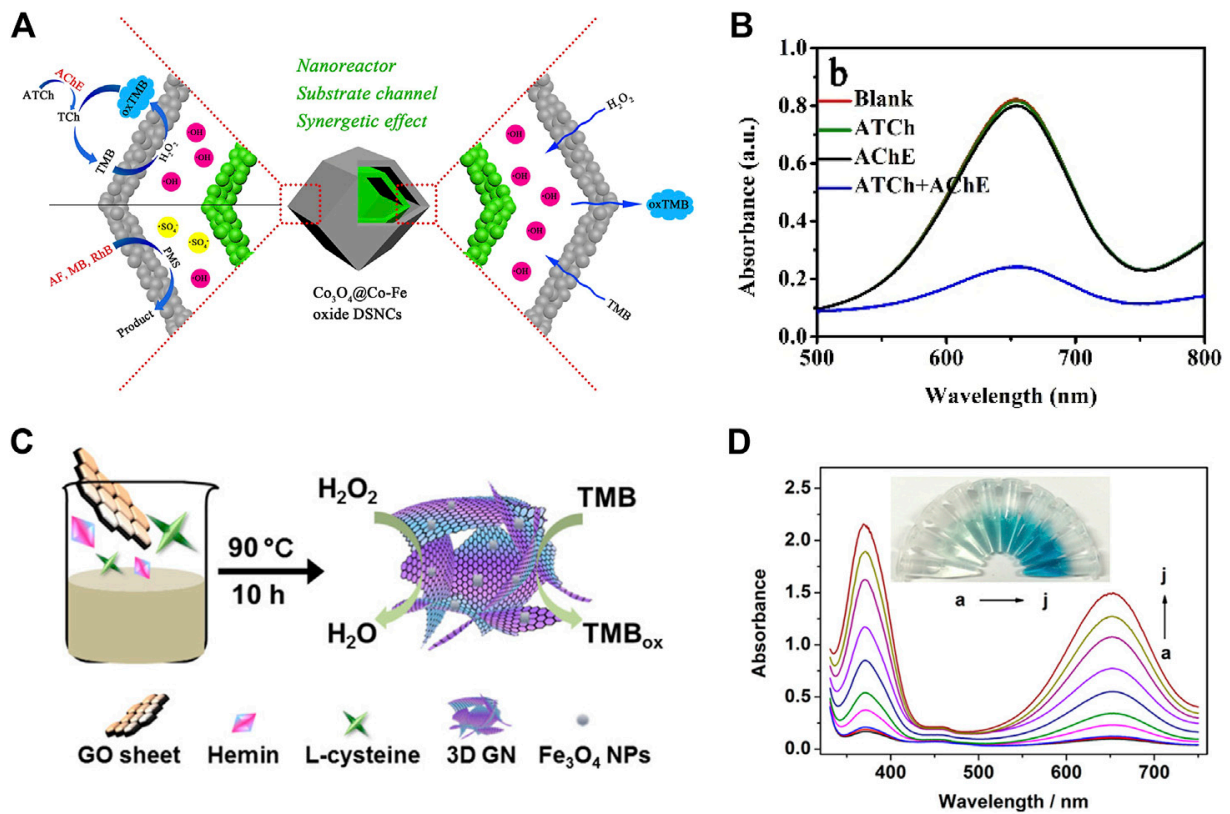

FIGURE 4 | The schematic diagram of $\mathrm{Co}_{3} \mathrm{O}_{4} @$ Co-Fe hybrids (A). UV-vis spectra of $\mathrm{Co}_{3} \mathrm{O}_{4} @$ @ Co-Fe oxide DSNCs $/ \mathrm{H}_{2} \mathrm{O}_{2} / \mathrm{TMB}$ system with $0.25 \mathrm{mM}$ ATCh, 1 mU $\mathrm{mL}^{-1}$ AChE, or $0.25 \mathrm{mM}$ ATCh $+1 \mathrm{mU} \mathrm{mL}{ }^{-1}$ AChE (B). Schematic Presentation for $\mathrm{Fe}_{3} \mathrm{O}_{4}$ NPs Loaded 3D Graphene Nanocomposites with POD-Like Activity (C); Absorption spectra of TMB with different glucose concentrations: 0, 0.005, 0.01, 0.05, 0.1, 0.2, 0.3, 0.5, 0.7, and $1.0 \mathrm{mM}$ (D). (A,B was reproduced with permission from Ref. (Chen Q et al., 2020). Copyright 2020 Elsevier. (C-D) was reproduced with permission from Ref. (Wang et al., 2017). Copyright 2017 American Chemistry Society).

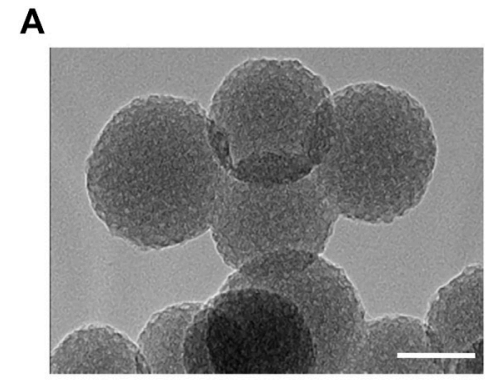

D

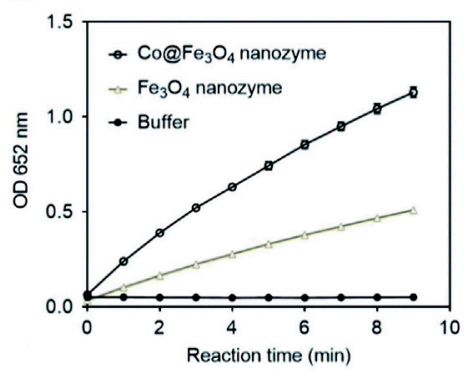

B

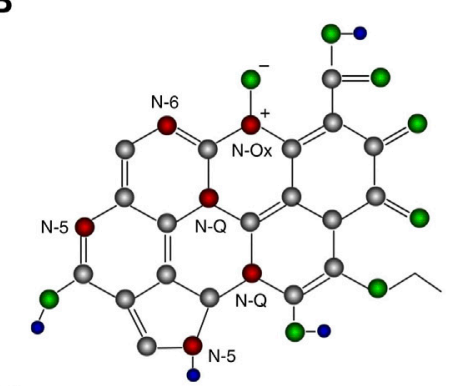

E

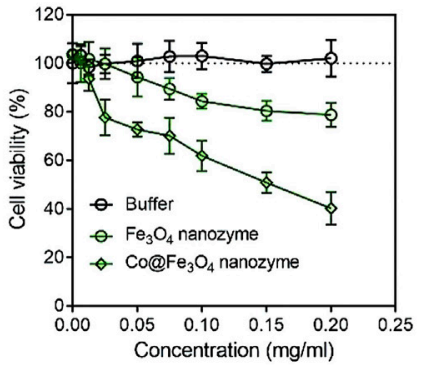

C

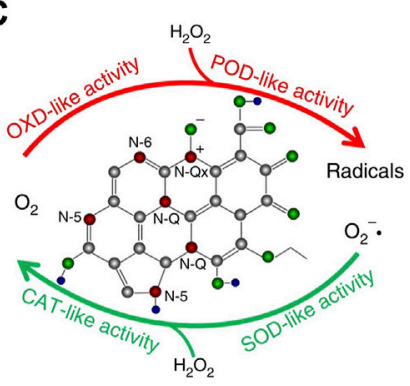

$\mathbf{F}$

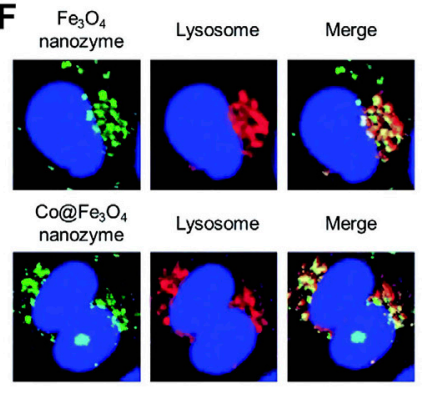

FIGURE 5 | Kinetics for OXD-like activity of N-PCNSs (A) Kinetics for POD-like activity of N-PCNSs (B). Schematic presentation of enzyme-like activities of $\mathrm{N}$-PCNSs (C). Comparison between the POD-like activities of the $\mathrm{Fe}_{3} \mathrm{O}_{4}$ and $\mathrm{Co} @ \mathrm{Fe}_{3} \mathrm{O}_{4}$ nanozymes (D). Cell viability of the human renal cancer cells A-498 incubated with the $\mathrm{Fe}_{3} \mathrm{O}_{4}$ and $\mathrm{Co} @ \mathrm{Fe}_{3} \mathrm{O}_{4}$ nanozymes. The buffer contained $10 \mathrm{nM} \mathrm{H}_{2} \mathrm{O}_{2}$ (E). Localization of the $\mathrm{Fe}_{3} \mathrm{O}_{4}$ and $\mathrm{Co} @ \mathrm{Fe}_{3} \mathrm{O}_{4}$ nanozymes in the A-498 cells (F). (A-C was reproduced with permission from Ref. (Fan et al., 2018). Copyright 2018 Nature Publishing Group. (D-F) was reproduced with permission from Ref. (Wang L et al., 2019). Copyright 2019 Royal Society of Chemistry). 

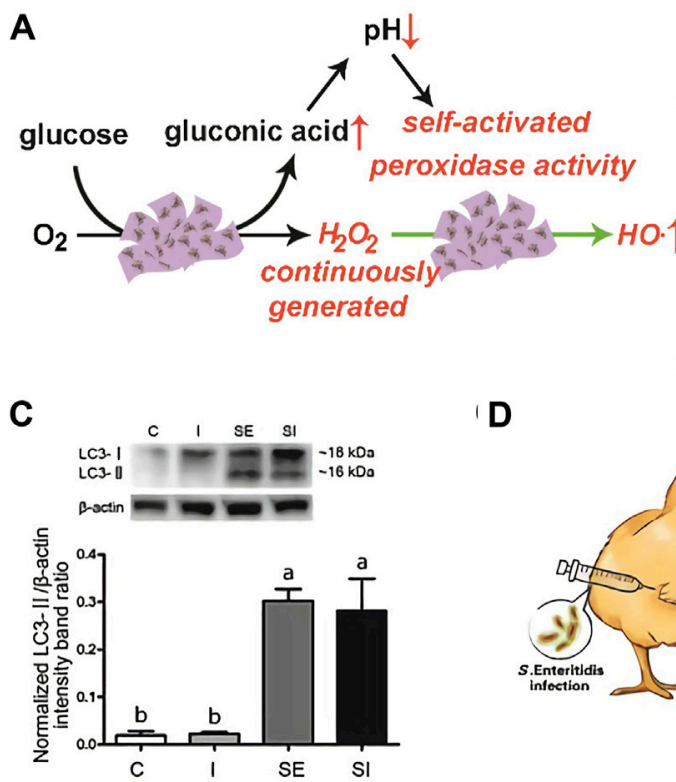

I

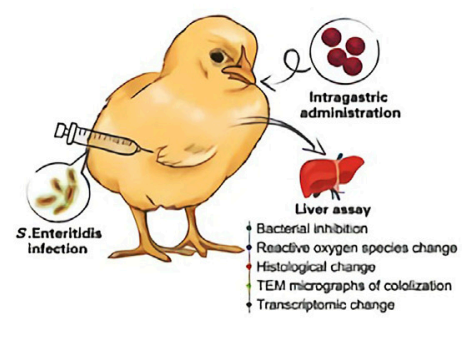

B
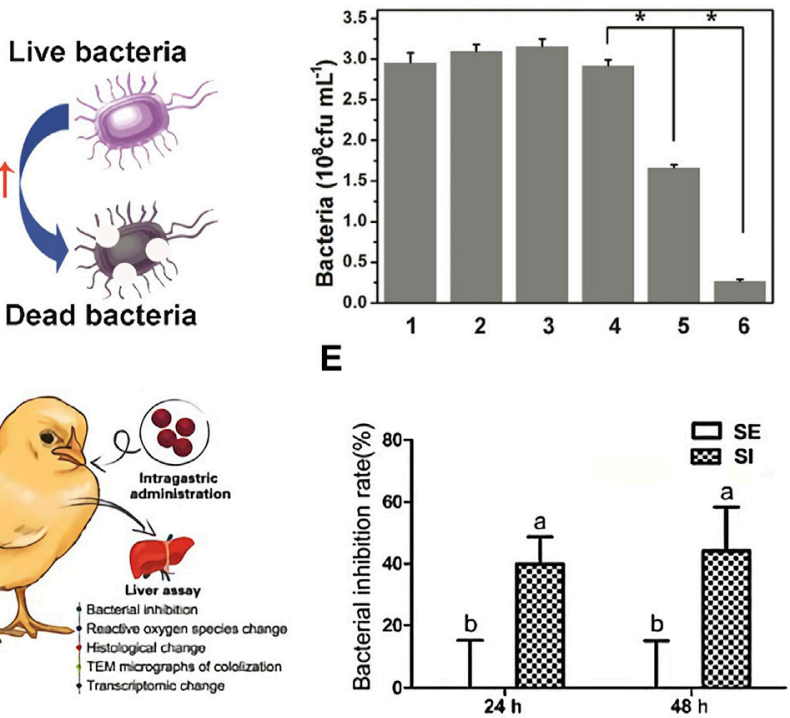

FIGURE 6 | The antibacterial mechanism of the 2D MOF/GOx hybrid nanocatalyst as a benign and self-activated cascade reagent (A). Viability analyses of $S$. aureus *Significantly different $(p<0.05)$ from data obtained. (B). The protein expression levels of LC3, a marker protein for autophagy, in LMH cells at 12 h (C). Schematic illustration of the animal experiment. Chicken were orally gavaged with ionzymes and subcutaneous injected with S. Enteritidis. Livers were collected for pathological analyses (D). Bacterial inhibition rates of ionzymes at different times in livers of S. Enteritidis infected chickens. Values represent the Mean \pm SEM $(n=9)$. Different letters indicate statistically significant difference $(p<0.05)$ (E). (A-C was reported with permission from Ref. (Liu et al., 2019) Copyright 2019 American Chemistry Society. D-E was reported with permission from Ref. (Shi et al., 2018) Copyright 2018 Ivyspring International.)

kinetics. Taking Au (111) surface as an example, under acidic or neutral conditions, $\mathrm{H}_{2} \mathrm{O}_{2}$ is adsorbed on $\mathrm{Au}$ (111) surface and a basic decomposition reaction occurs, resulting in the adsorption of oxygen species $\mathrm{O}^{*}\left({ }^{*}\right.$ means adsorption on the surface of the metal material). $\mathrm{O}^{*}$ can take hydrogen atoms make its oxidation reaction of organic substrates, presenting the POD activity. Under alkaline conditions, hydroxyl groups are pre-adsorbed on $\mathrm{Au}$ (111) surfaces. Under the action of $\mathrm{OH}^{*}, \mathrm{H}_{2} \mathrm{O}_{2}{ }^{*}$ occurs acid decomposition reaction, generating oxygen adsorption species $\mathrm{O}_{2}{ }^{*} \cdot \mathrm{O}_{2}{ }^{*}$ is released as $\mathrm{O}_{2}$ after separating from the metal surface, showing CAT-like activity. Among them, $\mathrm{OH}^{\star}$ is both an active site like CAT and an inhibitory site of POD activity (Sun et al., 2015). When $\mathrm{pH}$ increases, $\mathrm{H}_{2} \mathrm{O}_{2}{ }^{*}$ is more prone to occurs acid decomposition, leading to the decrease of POD-like activity and the promotion of CAT activity (Li J et al., 2015). Theoretical calculation also revealed that the greater the adsorption energy of hydrogen peroxide on the metal surface, the higher the catalytic activity of the metal, which provides a basis for rational design of nanozymes. Common noble metal nanozymes also contain Pd and Ag nanozymes, which own POD activity (Fu et al., 2015; Wen at al., 2015). Under neutral and alkaline conditions, Pd nanozymes exhibit CAT and SOD activities. Less reported, the single atomic nanozyme formed by Pd attached to ZIF- 8 has the dual functions of GPx and POD, which can convert GSH to GSSG when it reacts with $\mathrm{H}_{2} \mathrm{O}_{2}$ to generate $\cdot \mathrm{OH}$, thus achieving a variety of functions (Figure 2) (Chang et al., 2021).

\section{Carbon-Based Nanozymes}

Carbon-based nanomaterials, mainly include carbon nanotubes, graphene oxide, carbon nitrous oxide, carbon dots, fullerenes and their derivatives, have been broadly explored to mimic enzymelike activities. The categorical electronic and geometric structures endure carbon-based nanozymes with various enzyme activities. In fact, carbon-based nanozymes hold catalytic properties similar to those of natural enzymes and have been mentioned in early studies. As early as 1991, Fulleren for the first time was found to own the ability to scavenge free radicals (Krusic et al., 1991), but at that time, natural fullerenes were insoluble in water and were not widely concerned. Subsequently, graphene as a twodimensional carbon-based nanomaterial has aroused a lot of attention. Ren et al. designed a graphene oxide quantum dot with excellent CAT activity that effectively reduced Reactive oxygen species (ROS) content in PC12 cells (Ren et al., 2018). Even at low concentrations, its catalytic capacity is comparable to CAT $(4 \mathrm{U} / \mathrm{mL})$, making it an excellent enzyme substitute. In 2018, $\mathrm{Li}$ et al. reported of $\mathrm{Co}$ and $\mathrm{N}$ doped into porous car nanozyme (Co, N-HPC), which presenting excellent OXD activity (Li et al., 2018). They found that the pyridine $\mathrm{N}$ and pyrrole $\mathrm{N}$ atoms increased the electron state density and opened the band gap of graphene, which effectively promoted the electron transfer of nanozyme from catalyst to $\mathrm{O}_{2}$, thus enhancing the catalytic performance of graphene. Based on carbon-based nanozymes generally possessing POD activity, (Sun et al., 2018) reported the latest progress of this research group on the catalytic mechanism of carbon-based nanomaterials in 2010, and proposed that the POD activity of carbon-based nanomaterials lies in the carbonyl group $(\mathrm{C}=\mathrm{O})$ on the surface as the active site, and the carboxyl group (--COO-) as the binding site, which binds to $\mathrm{H}_{2} \mathrm{O}_{2}$ molecule and converts it into. $\mathrm{OH}$. With the further 


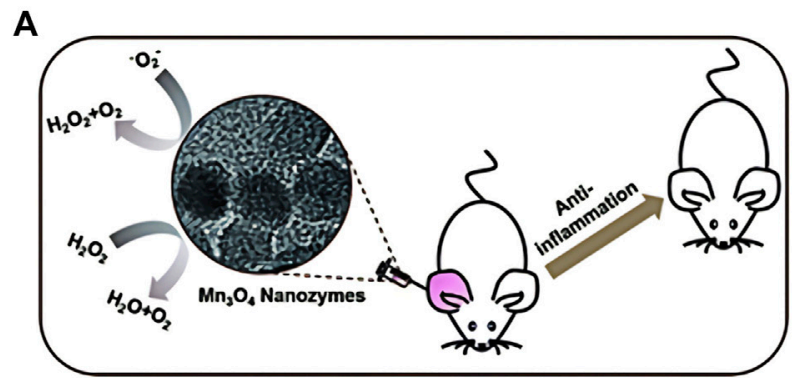

C

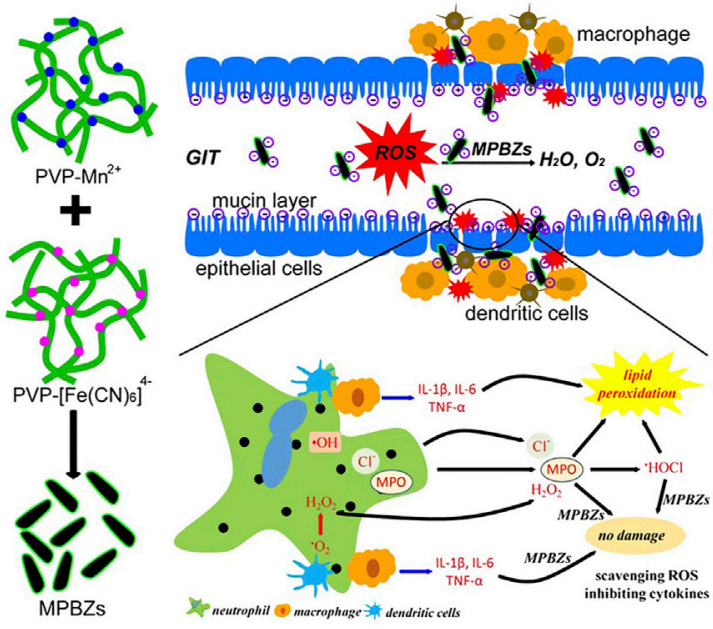

B SOD Concentration $(\mathrm{U} / \mathrm{mL})$

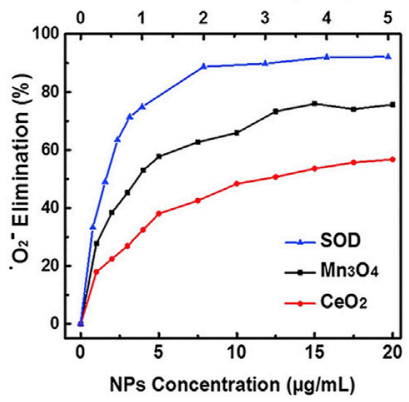

D

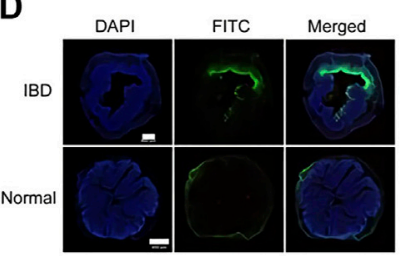

E

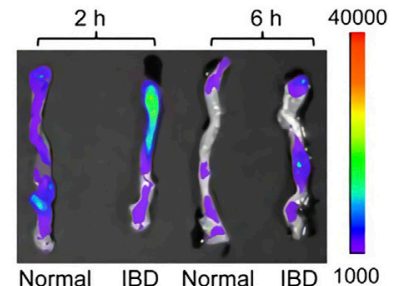

FIGURE 7 | The schematic diagram of $\mathrm{Mn}_{3} \mathrm{O}_{4}$ nanozymes (A). Dependence between the elimination of $\mathrm{O}_{2}$ - and concentrations of $\mathrm{Mn}_{3} \mathrm{O}_{4} \mathrm{NPs}, \mathrm{CeO}_{2} \mathrm{NPs}$, and natural SOD (B). Schematic diagram of the synthetic production of MPBZs. MPBZs modified with PVP were constructed via a simple but efficient strategy: mixing the manganese source solution with PVP and an $\left[\mathrm{Fe}(\mathrm{CN})^{6}\right]_{4}$ - source with PVP under magnetic stirring (C). Fluorescence imaging of colons from control mice and mice with DSS-induced colitis after oral FITC-labelled MPBZ treatment (D) Biodistribution images and in the colons of mice treated with MPBZs were carried out after oral administration of 2 and 6 h. Scale bar: 400 mm (E). (A,B was reported with permission from Ref. (Yao et al., 2018) Copyright 2018 Royal Society of Chemistry. C-E was reported with permission from Ref. (Zhao et al., 2019) Copyright 2019 Ivyspring International.)

exploration, carbon-based nanozymes will be applied in biological diagnostics and biosensing.

\section{APPLICATIONS}

\section{Nanozyme for Biosensing}

The detection of glucose in plasma is always of great significance for biosensing. On basis of the catalytic activity of nanozyme and the principle of glucose oxidation producing $\mathrm{H}_{2} \mathrm{O}_{2}$, the colorimetric detection method of $\mathrm{H}_{2} \mathrm{O}_{2}$ and glucose is expected to be utilized in practical application. At present, increasing studies have been reported on the application of nanozymes in biosensors, among which the most popular is the detection of $\mathrm{H}_{2} \mathrm{O}_{2}$ and glucose. Huang et al. devised $\mathrm{Co}_{3} \mathrm{O}_{4} @ \mathrm{Co}-\mathrm{Fe}$ oxide double-shell nanocages (DSNCS) by anion exchange combined with low temperature pyrolysis utilizing ZIF-67 as the starting template (Figure 3, Figures 4A,B) (Chen $H$ et al., 2020). The nanocages can maximize the advantage of hollow nanostructures that act as both nanoreactors and substrate channels to mimic enzymes. The excellent POD-like activity of $\mathrm{Co}_{3} \mathrm{O}_{4} @ \mathrm{Co}-\mathrm{Fe}$ oxide DSNC endures the linear detection with range of $\mathrm{H}_{2} \mathrm{O}_{2}$ from 0.02 to $600 \mu \mathrm{M}$, with the detection limit was $20 \mathrm{nM}$. Furthermore, $\mathrm{Co}_{3} \mathrm{O}_{4} @ \mathrm{Co}-\mathrm{Fe}$ oxide DSNC can activate PMS to degrade $99.1 \%$ of acidic fuchsin in $20 \mathrm{~min}$, and possess superior reusability in ten cycles of operation. Taking advantages of high POD activity of Graphene quantum dots (GQD), (Figures 4C,D) (Wang et al., 2017) designed a novel one-pan strategy to prepare $3 \mathrm{D}$ porous graphene (3D GN) loaded with $\mathrm{Fe}_{3} \mathrm{O}_{4}$ nanoparticles employing heme as the iron source. The obtained product (3D GH-5) presented superior POD activity. In comparison with the traditional 2D graphene-based nanocomposites, the introduced $3 \mathrm{D}$ porous structure significantly improved the catalytic activity, catalytic rate and affinity for the substrate. The high catalytic activity can be attributed to the formation of $\mathrm{Fe}_{3} \mathrm{O}_{4} \mathrm{NPs}$ and the 3D porous graphene structure.

Nanozymes were taken advantages of glucose detection when combined with GOD. GOD is able to catalyze the oxidation of glucose into gluconic acid and $\mathrm{H}_{2} \mathrm{O}_{2}$, and then nanozymes are utilized to detect $\mathrm{H}_{2} \mathrm{O}_{2}$ to obtain the glucose concentration indirectly (Wei and Wang, 2008). Zhang et al. reported a 3D $\mathrm{Fe}$ - and N-doped carbon structure (Fe-Phen-CFS) (Zhang et al., 
TABLE 1 | Types and applications of nanozymes.

\begin{tabular}{|c|c|c|c|c|c|}
\hline Nanomaterials & Enzyme activity & Applications & Ref. & $K_{\mathrm{M}}$ & $V_{\max }$ \\
\hline PEG/Ce-Bi@DMSN & POD/CAT & Catalytic oxidation for cancer therapy & 21 & $27.54 \mathrm{mM}$ & $3.85 \times 10^{-8} \mathrm{M} / \mathrm{s}$ \\
\hline $\mathrm{Fe}_{3} \mathrm{O}_{4} @ \mathrm{DMSN}$ & POD & Hydroxyl radical generation for cancer therapy & 27 & $10.93 \mathrm{mM}$ & $4.22 \times 10^{-8} \mathrm{M} / \mathrm{s}$ \\
\hline $\mathrm{V}_{2} \mathrm{O}_{5}$ & $\mathrm{GP} \times / \mathrm{GR}$ & Biological special applications & 31 & $\begin{array}{c}V_{N w},(44.4 \pm 1.7) \\
V_{S h},(57.3 \pm 3.8) \\
V_{N f}(92.5 \pm 3.4), \text { and } \\
V_{S p}(143.7 \pm 2.3),\end{array}$ & $\begin{array}{c}V_{N w},(192.3 \pm 6.6) \\
V_{S h},(233.1 \pm 16.3) \\
V_{N f}(340.1 \pm 21.3), \text { and } \\
V_{S p}(458.7 \pm 19.6),\end{array}$ \\
\hline $\mathrm{Pd}-\mathrm{ZIF}$ & $\mathrm{POD} / \mathrm{GPx}$ & Ferroptosis for cancer therapy & 39 & $0.24 \mathrm{mM}$ & $1.97 \times 10^{-5} \mathrm{M} / \mathrm{s}$ \\
\hline $\mathrm{Co}_{3} \mathrm{O}_{4} @ \mathrm{Co}-\mathrm{Fe}$ & POD & Biosensing and dye-degradation & 44 & $0.176(\mathrm{k} / \mathrm{min})$ & $3.93\left(t_{1 / 2}\right)$ \\
\hline $\mathrm{Fe}_{3} \mathrm{O}_{4}$-Graphene & SOD & Glucose detection & 45 & $1.39 \mathrm{mM}$ & $10.1 \times 10^{-8} \mathrm{M} / \mathrm{s}$ \\
\hline N-PCNSs & POD/OXD/CAT/SOD & Catalytic oxidation for cancer therapy & 54 & $0.1540 \mathrm{M}$ & $0.4720 \mathrm{mg} / \mathrm{L} / \mathrm{min}$ \\
\hline MSN-AuPs & POD/OXD & Anti-bacterials & 56 & $15.81 \mathrm{mM}$ & $17.3 \times 10^{-8} \mathrm{M} / \mathrm{s}$ \\
\hline Cu-TCPP & POD/GOX & Anti-bacterials & 57 & $\begin{array}{c}88-90 \% \text { Inactivation } \\
\text { of } \bullet \mathrm{OH}\end{array}$ & 80-100\% Catalytic activity \\
\hline IONzymes & SOD & Anti-bacterials & 58 & $259.7 \mathrm{mM}$ & $96.4 \mathrm{nM} / \mathrm{s}$ \\
\hline I-CDs & POD & Antifungal activity & 59 & $0.097 \mathrm{mM}$ & $27.86 \times 10^{-8} \mathrm{M} / \mathrm{s}$ \\
\hline $\mathrm{Mn}_{3} \mathrm{O}_{4}$ & SOD & Anti-inflammatory & 62 & $75 \%$ scavenging rate & / \\
\hline $\mathrm{Ce}_{0.7} \mathrm{Zr}_{0.3} \mathrm{O}_{2}$ & SOD & Anti-inflammatory & 63 & / & / \\
\hline MPBZs & SOD & Anti-inflammatory for colitis & 64 & / & / \\
\hline PB & SOD/CAT & Anti-inflammatory & 66 & $14.7 \mathrm{mM}$ & $1.15 \times 10^{-7} \mathrm{M} / \mathrm{s}$ \\
\hline
\end{tabular}

2015), which acts as a POD-mimic nanozyme for the detection of $\mathrm{H}_{2} \mathrm{O}_{2}$ and glucose. In the existence of $\mathrm{H}_{2} \mathrm{O}_{2}, \mathrm{Fe}-\mathrm{Phen}$-CFS is able to catalyze the conversion of the substrate to the fluorescence product of hydroxyl terzoic acid, realizing the quantitative detection of $\mathrm{H}_{2} \mathrm{O}_{2}$. The detection limitation is approximately $68 \mathrm{nM}$, and the linear range is $0.1-100 \mathrm{mM}$.

The application of nanozyme in biosensing also includes nucleic acid detection. Park et al. (2011) performed polymerase chain reaction (PCR) on the samples. If target DNA is present in the sample, a large amount of nucleic acid is produced and mixed with iron oxide nanoparticles to develop color. Through electrostatic interaction, the phosphoric acid skeleton will be adsorbed on the surface of the nanoparticles, resulting in the binding of the chromogenic substrate to the nano-enzyme for the detection of the target DNA. Similarly, in human urine Papillomavirus DNA (Brinkman et al., 2004) and Chlamydia trachomatis (Hafner et al., 2008) can also be detected by nanozyme. Wang et al. (2013) loaded ferroporphyrin and Streptomyces anti-biotin proteins onto nanozymes for electrochemical detection of target DNA. The hairpin DNA was fixed on the electrode modified by Au NPs nanozyme. When the target DNA was present in the sample, the hairpin DNA was opened and Streptomyces anti-biotin protein loaded on the nanozyme was bound to the biotin. In addition, aptamer can be combined with nano-enzyme to capture target protein, which is expected to replace the traditional detection of protein by antibody Methods. From what has been discussed above, the advantages such as high sensitivity, wide detection range and broad spectrum durability of organic nanozyme make it an important detection method for biosensing, which is expected to replace traditional detection methods using natural enzymes.

\section{Tumor Therapy}

Cancer is a global public health problem which endangers human life and health. (Erratum, 2020). There are growing methods for tumor therapies including chemotherapy, radiation therapy, photodynamic therapy, sonodynamic therapy and immunotherapy treatments. However, chemotherapy and radiotherapy always bring serious side effects, while $\mathrm{O}_{2^{-}}$ dependent photodynamic and sonodynamic therapy are difficult to cope with the hypoxic environment of tumors, which limit their applications in tumor suppression. Nanozymes are featured with various enzymatic activity, which not only can induce tumor cells apoptosis by catalyzing the generation of ROS storm, but also promote the generation of $\mathrm{O}_{2}$ to relieve the hypoxia tumor microenvironment, which making it a significant role in tumor treatment.

Quite a few nanozymes are able to exhibit POD and OXD activities in the acidic microenvironment of tumors (Figures 5D-F) (Wang L et al., 2019). They were endured with strong oxidizing ability and can catalyze endogenous $\mathrm{H}_{2} \mathrm{O}_{2}$ or $\mathrm{O}_{2}$ to produce a large number of free radicals to against tumor cells. Yan et al. prepared nitrogen-doped porous carbon nanospheres with 4 types of enzyme activities (OXD, POD, CAT and SOD) (Figures 5A-C) (Fan et al., 2018). The nanozyme possess POD and OXD activity under acid environments. While under neutral conditions, the nanozyme behave CAT and SOD activities, thus it has no obvious side effect on normal cells. In a tumor-bearing mice with diverse groups, the nanozyme treatment group significantly inhibited the growth of tumors, indicating the feasibility to employ nanozymes to suppress tumors. In another similar study, (Dong et al., 2020) designed Bi macroporous silicon loaded cerium oxide quantum dots (PEG/Ce-Bi@DMSN) to treat tumors depend on the POD and CAT and GPx activities, under neutral environment, the synthesized nanozyme can catalyze the decomposition of $\mathrm{H}_{2} \mathrm{O}_{2}$, while at acid environment, the POD and GPx activities endure nanozyme with $\mathrm{OH}$ generation and $\mathrm{GSH}$ depletion, triggering the cell apoptosis. The nanocatalytic enzyme platform provides a new conceptual framework for the treatment of tumors. 


\section{Antibacterial}

Bacterial infection has always been one of the major problems threatening human health. To date, a number of drugs or materials such as metal ions, quaternary ammonium ions, antibiotics and fungicides have been used to inhibit or reduce the growth of harmful bacteria. However, antibiotic resistance, complex production process and high cost hampers the application of traditional sterilizers. Similar to tumor therapy, the POD activity of nanozyme that catalyze $\mathrm{H}_{2} \mathrm{O}_{2}$ or $\mathrm{O}_{2}$ to produce a large number of ROS can achieve sterilization effect. At the same time, taking advantages of high stability, broad spectrum and low cost, nanozyme is expected to be a nova of sterilizer.

$\mathrm{Qu}$ et al. (Tao et al., 2015) constructed bifunctional mesoporous silica supported gold nanoparticles (MSN-AuPs), which possess both POD and OXD enzyme activities, and can be acted as a highly efficient ROS generating agent to kill bacteria. Moreover, since the ROS produced won excellent oxidative activity to nucleic acids, proteins and polysaccharides in the biofilm matrix, the antibacterial system can effectively break the existing biofilm while sterilizing, which prevent the formation of new biofilms. Most nanozymes with POD activity operate best in an acidic environment, which severely limits their application in neutral living systems. To break the limitation, Qu (Figure 6A-C) (Liu et al., 2019) synthesis and characterization of $2 \mathrm{D} \mathrm{Cu}-\mathrm{TCPP}(\mathrm{Fe})$ nanocrystal based on MOF and supported by GOD. Glucose can be converted to gluconic acid and $\mathrm{H}_{2} \mathrm{O}_{2}$ by GOD activity in vivo, and the resulting gluconic acid can reduce the microenvironment $\mathrm{pH}$ from 7 to 3-4, which significantly activate the POD activity of $2 \mathrm{D} \mathrm{Cu}-\mathrm{TCPP}(\mathrm{Fe})$ nanochips, leading to the generation of boosting $\bullet \mathrm{OH}$. Moreover, Gao group (Figures 6D,E) (Shi et al., 2018) employed ferric oxide nanozymes against intracellular Salmonella enteritidis. The peroxide-like activity of ferric oxide nanozymes significantly suppressed the activity of Salmonella enteritidis in cells, and then joint with the autophagy function of cells to kill bacteria.

Furthermore, Gao's team devised an antiviral strategy that utilized iron oxide nanozyme (ionzymes) to target the lipid envelope of influenza virus (Qin et al., 2019). They evaluated the antiviral activity of ionzymes by applying hemagglutination and the 50\% tissue culture infection dose (TCID50) assay, and malealdehyde (MDA) analysis collaborated with transmission electron microscopy (TEM) was used to analysis of lipid peroxidation in the viral envelope, and western blot were applied to detect the adjacent viral proteins. Ionzymes was demonstrated to be able to catalyze lipid peroxidation of the viral lipid envelope to inactivate the enveloped virus and provide protection from viral transmission and infection, verifying the inactivation of influenza A virus (IAV). Yang group developed a nitrogen and iodine-doped carbon spot (I-CD) as a peroxidasemimic (POD) nanozyme for antifungal disinfection of C. albicans (Li X et al., 2021). In the existence of exogenous $\mathrm{H}_{2} \mathrm{O}_{2}$, the prepared I-CDS samples presented a peroxidase activity, and the antifungal activity against Candida albicans was up to $90 \%$. The system promoted the formation of ROS, containing hydroxyl radical $(\cdot \mathrm{OH})$, which successfully inhibited the growth of Candida albicans. Nanozyme has been an ideal substitute for antibiotics for inhibiting resistant bacteria thanks to the mechanism of its action and broad spectrum and durability.

\section{Inflammation Elimination}

Inflammation is a normal immune response. Under normal circumstances, inflammation is beneficial and belongs to the automatic defense mechanism of body. But if it cannot be stopped in time, acute inflammation will develop into chronic inflammation or even cancer. The occurrence of inflammation is inseparable with excessive ROS production. Therefore, antioxidants are extremely significant in the treatment of inflammation (Poole et al., 2015). On this ground, Wei et al. prepared $\mathrm{Mn}_{3} \mathrm{O}_{4}$ nanoparticles, which own both CAT and SOD activities, and possess a clear effect on $\mathrm{O}_{2} \cdot-, \mathrm{H}_{2} \mathrm{O}_{2}$ and $\bullet \mathrm{OH}$ (Figures 7A,B) (Yao et al., 2018). The animal experiment results exhibited that $\mathrm{Mn}_{3} \mathrm{O}_{4}$ nanoparticles can effectively alleviate ear inflammation caused by abnormally elevated ROS in living mice. Besides, Hyeon et al. (Soh et al., 2017) prepared $\mathrm{Ce}_{0.7} \mathrm{Zr}_{0.3} \mathrm{O}_{2}$ nanoparticles that by introducing $\mathrm{Zr}^{4+}$, the nanozyme were endured with a higher $\mathrm{Ce}^{3+} / \mathrm{Ce}^{4+}$ ratio and accelerate the conversion speed of $\mathrm{Ce}^{4+}$ to $\mathrm{Ce}^{3+}$.In comparison with $\mathrm{CeO}_{2}$ nanoparticles alone, the ROS scavenging ability of the nanozyme is significantly promoted, which can regulate the inflammatory response at very low doses. The results demonstrated that in the two typical sepsis model, $\mathrm{Ce}_{0.7} \mathrm{Zr}_{0.3} \mathrm{O}_{2}$ is capable of lowering the mortality and systemic inflammation in mice by $60 \%$.

Except for eliminating ROS draw support with catalytic reactions, nanozymes is able to regulate the immune system and alleviate inflammation. Zheng et al. (Figures 7C-E) (Zhao et al., 2019) synthesized Prussian blue manganese nanozymes (MPBZs) with a variety of enzymatic activities. With its suitable size $(120 \mathrm{~nm})$ and negative charge effect, nanozyme can preferentially accumulate on the mucosal surface after oral administration.

Xiong et al. found that $\mathrm{Fe}_{2} \mathrm{O}_{3}$ dimercaptosuccinate nanoparticles can protect the heart from ischemic injury (Xiong et al., 2015). $\mathrm{Fe}_{2} \mathrm{O}_{3}$ NPs increased the activity of SOD and decreased the level of ROS when heart ischemia-reperfusion injury occurred. Zhang et al. (2016). demonstrated that PB NPs have been proved to possess SOD and CAT activities, and revealed that PB NPs can be an effective antioxidant to control ROSinduced cell damage. In vitro experiments verified that ROS levels increased in rat mesangial cells (HBZY-1 cells) stimulated by CDDP. However, PB NPs effectively inhibited ROS levels and increased cell viability. Based on these results, it is suggested that PB NPs may potentially inhibit the nephrotoxicity of CDDP. The antioxidant effect of PB NPs has also been confirmed in vivo inflammation experiments.

Gold nanozyme can also down-regulate ROS. Barathmanikanth et al. found that SOD activity was significantly enhanced in the diabetic treatment group treated with Au NPs compared with the diabetic control group (Barathmanikanth et al., 2010). The ability of $\mathrm{Au}$ NPs to reduce ROS levels in hyperglycemia is able to restore the antioxidant defense system, showing the prospect of inflammation elimination. 


\section{SUMMARY AND OUTLOOK}

Nanozymes are a class of nanomaterials with enzymatic activity. In comparison with natural enzymes, nanozymes own the merits of flexible composition design, high stability, simple preparation and adjustable catalytic activity. In this review, the application of nanozyme in the diseases therapy in recent years is summarized, and the three strategies of nanozyme in the treatment of diseases are introduced in detail. Although nanozymes have made up for many shortcomings of traditional pro-oxidants/antioxidants and are widely applied in the field of disease treatment, there are still a sea of problems needs to be counter urgently.

1) Catalytic activity: Compared with natural enzymes and organic catalysts, the catalytic activity and efficiency of nanozymes are relatively low, which severely limits their application in disease treatment. On this ground, there is an urgent need to develop nanozymes with high catalytic activity, to further improve the therapeutic effect. According to the characteristics of nanoenzyme, the activity of nano-enzyme can be promoted by adjusting its size, crystal morphology, composition, surface modification, and the construction of mixed nano-enzyme. In addition, the current research on nano-enzymes mainly focuses on the simulation of oxidoreductase and hydrolase, while the simulation of ligase and transferase, which also play a significant role in living organisms, is still unknown. Therefore, expanding the types of nanozyme will be the only way to expand the application of nano-enzyme. In order to achieve this goal, it is essential to possess a full understanding of the enzyme activity center of the natural enzyme, and then combine the existing synthetic methods to simulate the active center and assemble the material to realize the simulation of the catalytic activity. In terms of enzyme activity, another key issue is the regulation between the activities of multiple enzymes of nanozyme. At present, nanozyme mainly realizes the treatment of various diseases through its positive or reverse regulation of ROS. However, according to the above, a nanozyme often has multiple enzyme activities, so how to balance its antioxidantase-like enzyme and oxidase-promoting enzyme activities is of great significance to ensure accurate and stable therapeutic effects. Constructing environment-responsive nanozyme or modifying the surface of nanozyme are effective measures to solve this problem.

2) Safety: Although nanozymes present great potential in disease treatment, in order to truly develop into clinical applications in the future, research on their biosafety in vivo is essential. Different from traditional enzymes, nanozymes are mostly inorganic nanoparticles, which can enter lysosome, mitochondria or nucleus in cells, and may cause damage to cells by irreversible interaction with intracellular components. In addition, as a foreign substance, nanozymes may also lead to immune responses in the body. To address this problem, studies have demonstrated that coating the surface of nanoparticles with polymers such as polyethylene glycol, cell membrane to promote their biocompatibility. However, the ideal biocompatibility is still a challenge.

3) Particle Size: The blocked metabolism of nanoparticles in the body can also trigger potential body damage. Studies have confirmed that nanoparticles smaller than $10 \mathrm{~nm}$ tend to accumulate in bone marrow or be removed by kidney, while nanoparticles larger than $100 \mathrm{~nm}$ tend to accumulate in macrophages of liver or spleen and cause hepatotoxicity (Alexis et al., 2008; Jun et al., 2008). Therefore, designing nanozymes of reasonable size to achieve ideal results and reduce side effects will be the focus of future research.

3) Mechanism of Resistance to disease: To date, the mechanism of action of many nanozymes in disease treatment remains unclear. As an example, it has been reported in some literatures that the intracellular ROS level decreased and the tolerance to oxidative stress increased after nanoparticles were applied to cells (Li Y et al., 2015). Unfortunately, there is no conclusive evidence from these studies that the antioxidant enzyme activity of nanozyme plays a role in cell protection.

4) Other potential applications: micro/nanomotors, as an emerged new research aspect, attract global interests due to their great potential applications in environmental remediation and biomedical field. Enzymes, with intrinsic high catalytic ability and excellent biocompatibility, are nice candidates for the engines of micro/nanomotors (Chen H et al., 2020; Wang Y et al., 2019; Wang et al., 2020). However, the natural enzymes are also facing the limitations for harsh environmental influence, where nanozymes would address the problem with their advantages, thus could further facilitate the development of micro/ nanomotors, towards deep applications in biomedical fields.

In conclusion, the development of nanozymes with high enzyme activity, superior stability, selective specificity, excellent biosafety and applicability, as well as the further study of their catalytic mechanism to achieve the expansion of indications will be the research focus of the application of nanozymes in the field of disease treatment in the future.

\section{AUTHOR CONTRIBUTIONS}

ML, LT and YC designed this paper, ML and PW wrote this paper, DM drew designs, and GC reviewed and edited, All authors have read and agreed to the published version of the manuscript.

\section{FUNDING}

The National Natural Science Foundation of China (No. 82173153, 82174114), the Yu Wei Han Academician Outstanding Youth Development Fund (DQYWH201603), Ministry of Education Key Laboratory of Visceral Theory and Application of Chinese Medicine Open Fund Project (zyzx 2006), the Fundamental Research Funds for the Provincial Universities (JFYWH201901) and the Fundamental Research Funds for the Doctor (XQBSQDJ201901). Heilongjiang Provincial Natural Science Foundation (LH2019H006), Innovation Fund of Heilongjiang Federation of Trade Unions, Construction Project of Scientific Research and Innovation Team of Harbin Medical UniversityDaqing (HD-CXTD-202003), Key Discipline Construction Project of Harbin Medical University-Daqing (HD-ZDXK-202005). 


\section{REFERENCES}

Alexis, F., Pridgen, E., Molnar, L. K., and Farokhzad, O. C. (2008). Factors Affecting the Clearance and Biodistribution of Polymeric Nanoparticles. Mol. Pharmaceutics 5 (4), 505-515. doi:10.1021/mp800051m

Asati, A., Santra, S., Kaittanis, C., Nath, S., and Perez, J. M. (2009). Oxidase-Like Activity of Polymer-Coated Cerium Oxide Nanoparticles. Angew. Chem. Int. Edition 48 (13), 2308-2312. doi:10.1002/anie.200805279

Barathmanikanth, S., Kalishwaralal, K., Sriram, M., Pandian, S. R. K., Youn, H.-S., Eom, S., et al. (2010). Anti-oxidant Effect of Gold Nanoparticles Restrains Hyperglycemic Conditions in Diabetic Mice. J. Nanobiotechnol 8, 16. doi:10.1186/1477-3155-8-16

Brinkman, J. A., Rahmani, M. Z., Jones, W. E., Chaturvedi, A. K., and Hagensee, M. E. (2004). Optimization of PCR Based Detection of Human Papillomavirus DNA from Urine Specimens. J. Clin. Virol. 29 (4), 230-240. doi:10.1016/s13866532(03)00157-4

Chang, M., Hou, Z., Wang, M., Yang, C., Wang, R., Li, F., et al. (2021). Single-Atom Pd Nanozyme for Ferroptosis-Boosted Mild-Temperature Photothermal Therapy. Angew. Chem. Int. Ed. 60 (23), 12971-12979. doi:10.1002/ anie. 202101924

Chen, H., Li, W., Lin, Y., Wang, L., Liu, X., and Huang, X. (2020). Fusion-Induced Structural and Functional Evolution in Binary Emulsion Communities. Angew. Chem. Int. Ed. 59 (39), 16953-16960. doi:10.1002/anie.202004617

Chen, K., and Arnold, F. H. (2020). Engineering New Catalytic Activities in Enzymes. Nat. Catal. 3 (3), 203-213. doi:10.1038/s41929-019-0385-5

Chen, Q., Zhang, X., Li, S., Tan, J., Xu, C., and Huang, Y. (2020). MOF-derived Co3O4@Co-Fe Oxide Double-Shelled Nanocages as Multi-Functional Specific Peroxidase-like Nanozyme Catalysts for Chemo/biosensing and Dye Degradation. Chem. Eng. J. 395, 125130. doi:10.1016/j.cej.2020.125130

Chen, Z., Yin, J.-J., Zhou, Y.-T., Zhang, Y., Song, L., Song, M., et al. (2012). Dual Enzyme-like Activities of Iron Oxide Nanoparticles and Their Implication for Diminishing Cytotoxicity. ACS Nano 6 (5), 4001-4012. doi:10.1021/nn300291r

Comotti, M., Della Pina, C., Matarrese, R., and Rossi, M. (2004). The Catalytic Activity of ?Naked? Gold Particles. Angew. Chem. Int. Ed. 43 (43), 5812-5815. doi:10.1002/anie.200460446

Dong, S., Dong, Y., Jia, T., Liu, S., Liu, J., Yang, D., et al. (2020). GSH-Depleted Nanozymes with Hyperthermia-Enhanced Dual Enzyme-Mimic Activities for Tumor Nanocatalytic Therapy. Adv. Mater. 32 (42), 2002439. doi:10.1002/ adma.202002439

Erratum (2020). Erratum: Global Cancer Statistics 2018: GLOBOCAN Estimates of Incidence and Mortality Worldwide for 36 Cancers in 185 Countries. CA A. Cancer J. Clin. 70 (4), 313. doi:10.3322/caac.21609

Fan, K., Xi, J., Fan, L., Wang, P., Zhu, C., Tang, Y., et al. (2018). In Vivo guiding Nitrogen-Doped Carbon Nanozyme for Tumor Catalytic Therapy. Nat. Commun. 9, 11. doi:10.1038/s41467-018-03903-8

Fu, Y., Zhang, H., Dai, S., Zhi, X., Zhang, J., and Li, W. (2015). Glutathionestabilized Palladium Nanozyme for Colorimetric Assay of Silver(I) Ions. Analyst 140 (19), 6676-6683. doi:10.1039/c5an01103e

Gao, L.-Z., and Yan, X.-Y. (2013). Discovery and Current Application of Nanozyme. Acta Agronomica Sinica 40 (10), 892-902. doi:10.3724/ sp.J.1206.2013.00409

Gao, L., Zhuang, J., Nie, L., Zhang, J., Zhang, Y., Gu, N., et al. (2007). Intrinsic Peroxidase-like Activity of Ferromagnetic Nanoparticles. Nat. Nanotech 2 (9), 577-583. doi:10.1038/nnano.2007.260

Ghosh, S., Roy, P., Karmodak, N., Jemmis, E. D., and Mugesh, G. (2018). Nanoisozymes: Crystal-Facet-Dependent Enzyme-Mimetic Activity of V2 O5 Nanomaterials. Angew. Chem. Int. Ed. 57 (17), 4510-4515. doi:10.1002/ anie. 201800681

Hafner, L., Beagley, K., and Timms, P. (2008). Chlamydia trachomatis Infection: Host Immune Responses and Potential Vaccines. Mucosal Immunol. 1 (2), 116-130. doi:10.1038/mi.2007.19

He, W., Zhou, Y.-T., Wamer, W. G., Hu, X., Wu, X., Zheng, Z., et al. (2013). Intrinsic Catalytic Activity of Au Nanoparticles with Respect to Hydrogen Peroxide Decomposition and Superoxide Scavenging. Biomaterials 34 (3), 765-773. doi:10.1016/j.biomaterials.2012.10.010

Hu, Y., Fan, Y.-C., Jiang, X.-H., Zhou, L.-M., and Cheng, Z.-J. (2021). A Ratiometric Fluorescent Sensing of Proanthocyanidins by MnO2 Nanosheets
Simultaneously Tuning the Photoluminescence of Au/AgNCs and Thiamine. Talanta 234, 122607. doi:10.1016/j.talanta.2021.122607

Huo, M., Wang, L., Chen, Y., and Shi, J. (2017). Tumor-selective Catalytic Nanomedicine by Nanocatalyst Delivery. Nat. Commun. 8. doi:10.1038/s41467-017-00424-8

Jia, T., Xu, J., Dong, S., He, F., Zhong, C., Yang, G., et al. (2019). Mesoporous Cerium Oxide-Coated Upconversion Nanoparticles for Tumor-Responsive Chemo-Photodynamic Therapy and Bioimaging. Chem. Sci. 10 (37), 8618-8633. doi:10.1039/c9sc01615e

Jiao, X., Song, H., Zhao, H., Bai, W., Zhang, L., and Lv, Y. (2012). Well-redispersed Ceria Nanoparticles: Promising Peroxidase Mimetics for H2O2 and Glucose Detection. Anal. Methods 4 (10), 3261-3267. doi:10.1039/c2ay25511a

Jun, Y. W., Lee, J. H., and Cheon, J. (2008). Chemical Design of Nanoparticle Probes for High-Performance Magnetic Resonance Imaging. Angew. Chem. Int. Ed. 47 (28), 5122-5135. doi:10.1002/anie.200701674

Jv, Y., Li, B., and Cao, R. (2010). Positively-charged Gold Nanoparticles as Peroxidiase Mimic and Their Application in Hydrogen Peroxide and Glucose Detection. Chem. Commun. 46 (42), 8017-8019. doi:10.1039/c0cc02698k

Krusic, P. J., Wasserman, E., Keizer, P. N., Morton, J. R., and Preston, K. F. (1991). Radical Reactions of C 60. Science 254 (5035), 1183-1185. doi:10.1126/ science.254.5035.1183

Li, J., Liu, W., Wu, X., and Gao, X. (2015). Mechanism of pH-Switchable Peroxidase and Catalase-like Activities of Gold, Silver, Platinum and Palladium. Biomaterials 48, 37-44. doi:10.1016/j.biomaterials.2015.01.012

Li, L., Zhao, Y., Yan, X., Qi, X., Wang, L., Ma, R., et al. (2021). Development of a Terminal-Fixed Aptamer and a Label-free Colorimetric Aptasensor for Highly Sensitive Detection of Saxitoxin. Sensors Actuators B: Chem. 344, 130320. doi:10.1016/j.snb.2021.130320

Li, S., Wang, L., Zhang, X., Chai, H., and Huang, Y. (2018). A Co,N Co-doped Hierarchically Porous Carbon Hybrid as a Highly Efficient Oxidase Mimetic for Glutathione Detection. Sensors Actuators B: Chem. 264, 312-319. doi:10.1016/ j.snb.2018.03.015

Li, X., Wu, X., Yuan, T., Zhu, J., and Yang, Y. (2021). Influence of the Iodine Content of Nitrogen- and Iodine-Doped Carbon Dots as a Peroxidase Mimetic Nanozyme Exhibiting Antifungal Activity against C. Albicans. Biochem. Eng. J. 175, 108139. doi:10.1016/j.bej.2021.108139

Li, Y., He, X., Yin, J.-J., Ma, Y., Zhang, P., Li, J., et al. (2015). Acquired SuperoxideScavenging Ability of Ceria Nanoparticles. Angew. Chem. Int. Ed. 54 (6), 1832-1835. doi:10.1002/anie.201410398

Liang, M., and Yan, X. (2019). Nanozymes: From New Concepts, Mechanisms, and Standards to Applications. Acc. Chem. Res. 52 (8), 2190-2200. doi:10.1021/ acs.accounts.9b00140

Lin, X., Zhu, Z., Lin, D., Bao, Q., Gao, Y., Liu, Q., et al. (2021). Boosting the Oxidase-like Activity of Platinum Nanozyme in MBTH-TOOS Chromogenic System for Detection of Trypsin and its Inhibitor. Talanta 234, 122647. doi:10.1016/j.talanta.2021.122647

Liu, C., Zhang, M., Geng, H., Zhang, P., Zheng, Z., Zhou, Y., et al. (2021). NIR Enhanced Peroxidase-like Activity of Au@CeO2 Hybrid Nanozyme by Plasmon-Induced Hot Electrons and Photothermal Effect for Bacteria Killing. Appl. Catal. B: Environ. 295, 120317. doi:10.1016/j.apcatb.2021.120317

Liu, X., Li, D., Liang, Y., Lin, Y., Liu, Z., Niu, H., et al. (2021a). Establishment of Anti-oxidation Platform Based on Few-Layer Molybdenum Disulfide Nanosheet-Coated Titanium Dioxide Nanobelt Nanocomposite. J. Colloid Interf. Sci. 601, 167-176. doi:10.1016/j.jcis.2021.05.056

Liu, X., Tian, M., Li, C., and Tian, F. (2021b). Polyvinylpyrrolidone-stabilized Pt Nanoclusters as Robust Oxidase Mimics for Selective Detection of Ascorbic Acid. Colloids Surf. A: Physicochemical Eng. Aspects 625, 126985. doi:10.1016/ j.colsurfa.2021.126985

Liu, X., Yan, Z., Zhang, Y., Liu, Z., Sun, Y., Ren, J., et al. (2019). Two-dimensional Metal-Organic Framework/enzyme Hybrid Nanocatalyst as a Benign and SelfActivated cascade Reagent for In Vivo Wound Healing. ACS Nano 13, 5222-5230. doi:10.1021/acsnano.8b09501

Liu, Y., Qin, Y., Zhang, Q., Zou, W., Jin, L., and Guo, R. (2021). Arginine-rich Peptide/platinum Hybrid Colloid Nanoparticle Cluster: A Single Nanozyme Mimicking Multi-Enzymatic cascade Systems in Peroxisome. J. Colloid Interf. Sci. 600, 37-48. doi:10.1016/j.jcis.2021.05.025

Lv, W., Cao, M., Liu, J., Hei, Y., and Bai, J. (2021). Tumor MicroenvironmentResponsive Nanozymes Achieve Photothermal-Enhanced Multiple Catalysis against Tumor Hypoxia. Acta Biomater. doi:10.1016/j.actbio.2021.08.015 
Meng, X., Fan, K., and Yan, X. (2019). Nanozymes: an Emerging Field Bridging Nanotechnology and Enzymology. Sci. China Life Sci. 62 (11), 1543-1546. doi:10.1007/s11427-019-1557-8

Park, K. S., Kim, M. I., Cho, D.-Y., and Park, H. G. (2011). Label-Free Colorimetric Detection of Nucleic Acids Based on Target-Induced Shielding against the Peroxidase-Mimicking Activity of Magnetic Nanoparticles. Small 7 (11), 1521-1525. doi:10.1002/smll.201001886

Poole, K. M., Nelson, C. E., Joshi, R. V., Martin, J. R., Gupta, M. K., Haws, S. C., et al. (2015). ROS-responsive Microspheres for on Demand Antioxidant Therapy in a Model of Diabetic Peripheral Arterial Disease. Biomaterials 41, 166-175. doi:10.1016/j.biomaterials.2014.11.016

Qin, T., Ma, R., Yin, Y., Miao, X., Chen, S., Fan, K., et al. (2019). Catalytic Inactivation of Influenza Virus by Iron Oxide Nanozyme. Theranostics 9 (23), 6920-6935. doi:10.7150/thno.35826

Ren, C., Hu, X., and Zhou, Q. (2018). Graphene Oxide Quantum Dots Reduce Oxidative Stress and Inhibit Neurotoxicity In Vitro and In Vivo through Catalase-like Activity and Metabolic Regulation. Adv. Sci. 5 (5), 1700595. doi:10.1002/advs.201700595

Sang, Y., Cao, F., Li, W., Zhang, L., You, Y., Deng, Q., et al. (2020). Bioinspired Construction of a Nanozyme-Based $\mathrm{H} 2 \mathrm{O} 2$ Homeostasis Disruptor for Intensive Chemodynamic Therapy. J. Am. Chem. Soc. 142 (11), 5177-5183. doi:10.1021/ jacs.9b12873

Shi, S., Wu, S., Shen, Y., Zhang, S., Xiao, Y., He, X., et al. (2018). Iron Oxide Nanozyme Suppresses Intracellular Salmonella Enteritidis Growth and Alleviates Infection In Vivo. Theranostics 8 (22), 6149-6162. doi:10.7150/ thno. 29303

Soh, M., Kang, D.-W., Jeong, H.-G., Kim, D., Kim, D. Y., Yang, W., et al. (2017). Ceria-Zirconia Nanoparticles as an Enhanced Multi-Antioxidant for Sepsis Treatment. Angew. Chem. Int. Ed. 56 (38), 11399-11403. doi:10.1002/ anie.201704904

Su, B., Xu, H., Xie, G., Chen, Q., Sun, Z., Cao, H., et al. (2021). Generation of a Nanobody-Alkaline Phosphatase Fusion and its Application in an Enzyme cascade-amplified Immunoassay for Colorimetric Detection of Alpha Fetoprotein in Human Serum. Spectrochimica Acta A: Mol. Biomol. Spectrosc. 262, 120088. doi:10.1016/j.saa.2021.120088

Sun, H., Zhao, A., Gao, N., Li, K., Ren, J., and Qu, X. (2015). Deciphering a Nanocarbon-Based Artificial Peroxidase: Chemical Identification of the Catalytically Active and Substrate-Binding Sites on Graphene Quantum Dots. Angew. Chem. Int. Ed. 54 (24), 7176-7180. doi:10.1002/ anie. 201500626

Sun, H., Zhou, Y., Ren, J., and Qu, X. (2018). Carbon Nanozymes: Enzymatic Properties, Catalytic Mechanism, and Applications. Angew. Chem. Int. Ed. 57 (30), 9224-9237. doi:10.1002/anie.201712469

Tao, Y., Ju, E., Ren, J., and Qu, X. (2015). Bifunctionalized Mesoporous SilicaSupported Gold Nanoparticles: Intrinsic Oxidase and Peroxidase Catalytic Activities for Antibacterial Applications. Adv. Mater. 27 (6), 1097-1104. doi:10.1002/adma.201405105

Wang, L., Hortelão, A. C., Huang, X., and Sánchez, S. (2019). Lipase-Powered Mesoporous Silica Nanomotors for Triglyceride Degradation. Angew. Chem. Int. Ed. 58 (24), 7992-7996. doi:10.1002/anie.201900697

Wang, L., Marciello, M., Estévez-Gay, M., Soto Rodriguez, P. E. D., Luengo Morato, Y., Iglesias-Fernández, J., et al. (2020). Enzyme Conformation Influences the Performance of Lipase-powered Nanomotors. Angew. Chem. Int. Ed. 59 (47), 21080-21087. doi:10.1002/anie.202008339

Wang, Q., Lei, J., Deng, S., Zhang, L., and Ju, H. (2013). Graphene-supported Ferric Porphyrin as a Peroxidase Mimic for Electrochemical DNA Biosensing. Chem. Commun. 49 (9), 916-918. doi:10.1039/c2cc37664d

Wang, Q., Zhang, X., Huang, L., Zhang, Z., and Dong, S. (2017). One-Pot Synthesis of Fe3O4 Nanoparticle Loaded 3D Porous Graphene Nanocomposites with Enhanced Nanozyme Activity for Glucose Detection. ACS Appl. Mater. Inter. 9 (8), 7465-7471. doi:10.1021/acsami.6b16034

Wang, Y., Li, H., Guo, L., Jiang, Q., and Liu, F. (2019). A Cobalt-Doped Iron Oxide Nanozyme as a Highly Active Peroxidase for Renal Tumor Catalytic Therapy. RSC Adv. 9, 18815-18822. doi:10.1039/C8RA05487H

Wei, H., and Wang, E. (2008). Fe3O4 Magnetic Nanoparticles as Peroxidase Mimetics and Their Applications in $\mathrm{H} 2 \mathrm{O} 2$ and Glucose Detection. Anal. Chem. 80 (6), 2250-2254. doi:10.1021/ac702203f
Wei, H., and Wang, E. (2013). Nanomaterials with Enzyme-like Characteristics (Nanozymes): Next-Generation Artificial Enzymes. Chem. Soc. Rev. 42 (14), 6060-6093. doi:10.1039/c3cs35486e

Wen, T., He, W., Chong, Y., Liu, Y., Yin, J.-J., and Wu, X. (2015). Exploring Environment-dependent Effects of Pd Nanostructures on Reactive Oxygen Species (ROS) Using Electron Spin Resonance (ESR) Technique: Implications for Biomedical Applications. Phys. Chem. Chem. Phys. 17 (38), 24937-24943. doi:10.1039/c5cp04046a

Wu, C.-Y., Hsu, Y.-H., Chen, Y., Yang, L.-C., Tseng, S.-C., Chen, W.-R., et al. (2021). Robust O2 Supplementation from a Trimetallic Nanozyme-Based SelfSufficient Complementary System Synergistically Enhances the Starvation/ Photothermal Therapy against Hypoxic Tumors. ACS Appl. Mater. Inter. 13 (32), 38090-38104. doi:10.1021/acsami.1c10656

Wu, J., Wang, X., Wang, Q., Lou, Z., Li, S., Zhu, Y., et al. (2019). Nanomaterials with Enzyme-like Characteristics (Nanozymes): Next-Generation Artificial Enzymes (II). Chem. Soc. Rev. 48 (4), 1004-1076. doi:10.1039/c8cs00457a

Xiong, F., Wang, H., Feng, Y., Li, Y., Hua, X., Pang, X., et al. (2015). Cardioprotective Activity of Iron Oxide Nanoparticles. Sci. Rep. 5. doi:10.1038/srep08579

Xu, J., Xing, Y., Liu, Y., Liu, M., and Hou, X. (2021). Facile In Situ Microwave Synthesis of Fe3O4@MIL-100(Fe) Exhibiting Enhanced Dual Enzyme Mimetic Activities for Colorimetric Glutathione Sensing. Analytica Chim. Acta 1179, 338825. doi:10.1016/j.aca.2021.338825

Yao, J., Cheng, Y., Zhou, M., Zhao, S., Lin, S., Wang, X., et al. (2018). ROS Scavenging Mn3O4nanozymes Forin Vivoanti-Inflammation. Chem. Sci. 9 (11), 2927-2933. doi:10.1039/c7sc05476a

Yuan, A., Xia, F., Bian, Q., Wu, H., Gu, Y., Wang, T., et al. (2021). Ceria NanozymeIntegrated Microneedles Reshape the Perifollicular Microenvironment for Androgenetic Alopecia Treatment. ACS nano 15, 13759-13769. doi:10.1021/ acsnano.1c05272

Zhang, J., Lin, Y., Wu, S., Hou, X., Zheng, C., Wu, P., et al. (2021). Self-photooxidation for Extending Visible Light Absorption of Carbon Dots and Oxidaselike Activity. Carbon 182, 537-544. doi:10.1016/j.carbon.2021.06.053

Zhang, R., He, S., Zhang, C., and Chen, W. (2015). Three-dimensional Fe- and N-Incorporated Carbon Structures as Peroxidase Mimics for Fluorescence Detection of Hydrogen Peroxide and Glucose. J. Mater. Chem. B 3 (20), 4146-4154. doi:10.1039/c5tb00413f

Zhang, W., Hu, S., Yin, J.-J., He, W., Lu, W., Ma, M., et al. (2016). Prussian Blue Nanoparticles as Multienzyme Mimetics and Reactive Oxygen Species Scavengers. J. Am. Chem. Soc. 138 (18), 5860-5865. doi:10.1021/jacs.5b12070

Zhang, Y., Yang, S., Wang, J., Cai, Y., Niu, L., Liu, X., et al. (2021). Copper Sulfide Nanoclusters with Multi-enzyme-like Activities and its Application in Acid Phosphatase Sensing Based on Enzymatic cascade Reaction. Talanta 233, 122594. doi:10.1016/j.talanta.2021.122594

Zhao, J., Gao, W., Cai, X., Xu, J., Zou, D., Li, Z., et al. (2019). Nanozyme-mediated Catalytic Nanotherapy for Inflammatory Bowel Disease. Theranostics 9 (10), 2843-2855. doi:10.7150/thno.33727

Zhu, Q., Yang, J., Peng, Z., He, Z., Chen, W., Tang, H., et al. (2021). Selective Detection of Glutathione by Flower-like NiV2O6 with Only Peroxidase-like Activity at Neutral pH. Talanta 234, 122645. doi:10.1016/j.talanta.2021.122645

Conflict of Interest: The authors declare that the research was conducted in the absence of any commercial or financial relationships that could be construed as a potential conflict of interest.

Publisher's Note: All claims expressed in this article are solely those of the authors and do not necessarily represent those of their affiliated organizations, or those of the publisher, the editors and the reviewers. Any product that may be evaluated in this article, or claim that may be made by its manufacturer, is not guaranteed or endorsed by the publisher.

Copyright (๑) 2021 Wang, Min, Chen, Li, Tong and Cao. This is an open-access article distributed under the terms of the Creative Commons Attribution License (CC BY). The use, distribution or reproduction in other forums is permitted, provided the original author(s) and the copyright owner(s) are credited and that the original publication in this journal is cited, in accordance with accepted academic practice. No use, distribution or reproduction is permitted which does not comply with these terms. 